\title{
Frequent copy number gains of SLC2A3 and ETV1 in testicular embryonal carcinomas
}

\author{
Andreas M Hoff1,*, Sigrid M Kraggerud D1,*, Sharmini Alagaratnam1,*, Kaja C G Berg1, Bjarne Johannessen1, \\ Maren Høland ${ }^{1,2}$, Gro Nilsen³, Ole C Lingjærde ${ }^{3}$, Peter W Andrews ${ }^{4}$, Ragnhild A Lothe ${ }^{1,2, \dagger}$ and Rolf I Skotheim (D)1,3,t \\ 'Department of Molecular Oncology, Institute for Cancer Research, The Norwegian Radium Hospital, Oslo University Hospital, Oslo, Norway \\ 2Institute for Clinical Medicine, Faculty of Medicine, University of Oslo, Oslo, Norway \\ 3Department of Informatics, Faculty of Mathematics and Natural Sciences, University of Oslo, Oslo, Norway \\ ${ }^{4}$ The Centre for Stem Cell Biology, Department of Biomedical Science, The University of Sheffield, Sheffield, UK
}

Correspondence should be addressed to R A Lothe or R I Skotheim: ragnhild.a.lothe@rr-research.no or rolf.i.skotheim@rr-research.no

*(A M Hoff, S M Kraggerud and S Alagaratnam contributed equally to this work)

${ }^{\dagger}(\mathrm{R}$ A Lothe and R I Skotheim contributed equally to this work)

\begin{abstract}
Testicular germ cell tumours (TGCTs) appear as different histological subtypes or mixtures of these. They show similar, multiple DNA copy number changes, where gain of $12 p$ is pathognomonic. However, few high-resolution analyses have been performed and focal DNA copy number changes with corresponding candidate target genes remain poorly described for individual subtypes. We present the first high-resolution DNA copy number aberration (CNA) analysis on the subtype embryonal carcinomas (ECS), including 13 primary ECs and 5 EC cell lines. We identified recurrent gains and losses and allelespecific CNAs. Within these regions, we nominate 30 genes that may be of interest to the EC subtype. By in silico analysis of data from 150 TGCTs from The Cancer Genome Atlas (TCGA), we further investigated CNAs, RNA expression, somatic mutations and fusion transcripts of these genes. Among primary ECs, ploidy ranged between 2.3 and 5.0, and the most common aberrations were DNA copy number gains at chromosome (arm) 7, 8, $12 p$, and 17, losses at 4, 10,11, and 18, replicating known TGCT genome characteristics. Gain of whole or parts of $12 p$ was found in all samples, including a highly amplified 100 kbp segment at 12p13.31, containing SLC2A3. Gain at 7p21, encompassing ETV1, was the second most frequent aberration. In conclusion, we present novel CNAs and the genes located within these regions, where the copy number gain of SLC2A3 and ETV1 are of interest, and which copy number levels also correlate with expression in TGCTs.
\end{abstract}

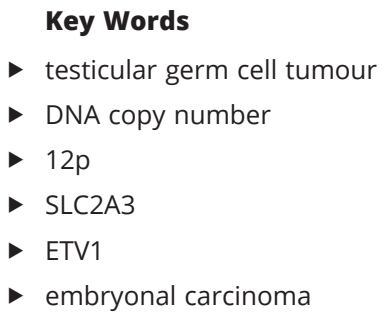

\section{Introduction}

Patients with testicular germ cell tumours (TGCTs) have good prognosis due to high sensitivity to platinum-based chemotherapy (Voutsadakis 2014). The Surveillance, Epidemiology, and End Results (SEER) program (2008-2014) reported a 5-year survival rate of $95.3 \%$ for patients with all tumour stages and $73.7 \%$ for those with distant metastasis (Noone et al. 2018). However, long-term side effects and morbidity after chemotherapy is a problem in this young patient group, and therefore, research is essential (Oldenburg et al. 2007, Kraggerud et al. 2009). Young Caucasian men have the highest TGCT incidence (Rosen et al. 2011) with an unexplained, marked increase https://erc bioscientifica.com

https://doi.org/10.1530/ERC-20-0064
(2) 2020 The authors Published by Bioscientifica Ltd. Printed in Great Britain

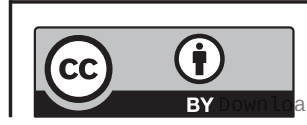

This work is licensed under a Creative Commons Attribution 4.0 International License. 
over the last 50 years, especially in industrialized countries. Genome-wide association studies (GWAS) and large-scale meta-analyses (Chung et al. 2013, Rajpert-De Meyts et al. 2016, Litchfield et al. 2017, Wang et al. 2017) have identified above 40 susceptibility loci. The mutation load has been found to be low, comparable to paediatric cancer types (Brabrand et al. 2015, Litchfield et al. 2015), but TGCTs are characterized by aneuploidy and a high degree of DNA copy number changes (Oosterhuis et al. 1989, Lothe et al. 1995, Taylor-Weiner et al. 2016).

TGCTs can be divided into two main histological types, seminomas and non-seminomas, with the latter comprising embryonal carcinomas (ECs), teratomas, choriocarcinomas, and yolk sac tumours. The various histological subtypes of TGCT have remarkably similar DNA copy number aberration (CNA) patterns, although some particular differences have been described (Kraggerud et al. 2002, Skotheim et al. 2006, Korkola et al. 2008). The isochromosome 12p and/or gain of $12 p$ sequences are pathognomonic to TGCT and used for diagnostic purposes for extragonadal tumours of unknown origin (Sandberg et al. 1996). Most genome-wide DNA copy number studies of TGCTs to date have been performed using relatively low-resolution technologies, but recently TCGA published a multilevel genomics paper, including next-generation sequencing and highresolution single nucleotide polymorphisms (SNPs) microarray analysis of 150 TGCTs, including 27 tumours classified as EC (18 pure EC and 9 mixed) according to the International Classification of Diseases for Oncology (ICD-O) morphological codes (Shen et al. 2018).

EC is a pluripotent histological subtype of TGCT that can be present alone or as one of several components in the tumour. ECs can be considered the malignant counterpart of embryonic stem (ES) cells, as both are pluripotent and have the capacity to differentiate. Identification of molecular differences between the two cell types may help resolve tumourigenic mechanisms and cellular pathways involved. We previously identified a discriminating gene expression signature between EC and ES cell lines, including a number of pluripotency and cancer-related genes (Alagaratnam et al. 2013). ES cell lines have been characterized for DNA CNAs on high-resolution SNP platforms (Närvä et al. 2010, Amps et al. 2011), where several higher-passage cells showed aberrations similar to those in TGCTs (Baker et al. 2007).

In this study, we profiled 13 pure primary EC tumours, as well as 12 cell lines (5 EC and 7 ES) on the high-resolution, whole-genome Affymetrix SNP 6.0 DNA copy number platform. We present a comprehensive overview of the EC subtype, identifying recurring regions of loss of heterozygosity (LOH) and focal regions of gains and losses, which harbour genes that may be of importance in EC development. These genes were further investigated in publically available multi-omics datasets and a transcriptional impact was confirmed for several of the genes.

\section{Materials and methods}

\section{Sample preparations}

Genomic DNA from 13 primary ECs had previously been isolated by phenol/chloroform extraction. Tumour percentage was estimated by an experienced pathologist on the basis of haematoxylin and eosin stained sections for 10/13 samples. For each case, the tumour percentage was calculated as the average of the tumour percentage of three sections, taken at either end and in the middle of the tumour sample used for DNA isolation. The median pathology tumour percentage was $49 \%$, and ranged from $22 \%$ to $78 \%$. Ten of the 13 primary ECs included in the current study have previously been analysed by chromosomal comparative genomic hybridization (cCGH; $n=6$, Kraggerud et al. 2002) and array CGH (aCGH; $n=5$, Skotheim et al. 2006), with one sample (EC no. 1838) analysed with both technologies.

Genomic DNA was isolated from five EC cell lines (NTERA2, 2102Ep, 833KE, TERA1, and NCCIT) and seven early-passage ( $<50$ passages) ES cell lines (Shef3, Shef4, Shef6, Shef7, H7, H9, and H14 using the AllPrep DNA/RNA Mini kit (Qiagen). All cell lines were cultured, sorted by the SSEA3-antigen, and fingerprinted by analysis of short tandem repeats as previously described (Alagaratnam et al. 2013).

\section{DNA copy number profiling of primary tumours and cell lines}

Three sets of samples were analysed for genome-wide DNA copy number on Affymetrix SNP 6.0 microarrays: primary EC tumours $(n=13)$, EC cell lines $(n=5)$, and ES cell lines $(n=7)$. For each sample, $500 \mathrm{ng}$ of genomic DNA was used as input for the Cytogenetics Copy Number Assay protocol for Genome-Wide Human SNP 6.0 arrays (Thermo Fisher Scientific). The samples were individually processed and hybridized as described in the Affymetrix Cytogenetics Copy Number Assay User Guide (P/N 702607 Rev. 2).

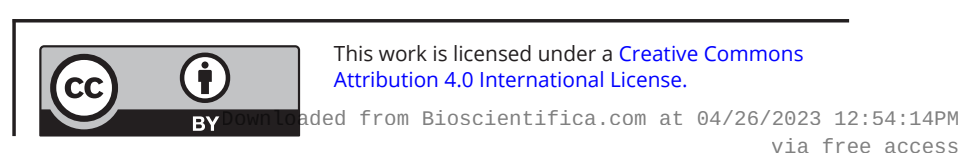




\section{Data processing, target region analysis and statistics}

The resulting cell intensity (CEL) files after hybridization were within recommended QC thresholds ( $\mathrm{CQC}>0.4$; MAPD <0.35). Signal extraction and pre-processing of the raw data was performed using the PennCNV protocol modified for Affymetrix genotyping arrays with Affymetrix Power Tools version 1.15.0 as described earlier (Sveen et al. 2016). HapMap samples previously analysed on the SNP Array $6.0(n=270)$, were used as reference for normalization, $\log \mathrm{R}$ ratio (LRR), and B-allele frequency (BAF) calculation. Probes targeting the allosomes, control probes $(n=3643)$, duplicate probes (one of the two probes covering overlapping genomic loci $(n=187)$, and probes mapping to regions with recurrent high frequency aberrations in non-cancer samples from several organs $(n=6668)$ were removed (Sveen et al. 2016).

For copy number analysis, preprocessed LRR data results from primary tumours and cell lines were used for single-sample segmentation, using the Piecewise Constant Fitting (PCF) algorithm in the $\mathrm{R}$ package copynumber (version 1.14.0). The user-defined penalty parameter $\gamma$ was set to 100 and the minimum number of probes per segment, $\mathrm{k}_{\min }$ was set to 5 . PCF segments with copy number estimates $\geq 0.15$ were called as gains and segments with estimates $\leq-0.15$ were called as losses. The results were visualized using the copynumber R package. In addition, CNAs (gains, amplifications (defined as high gains $>0.45$ ), and deletions) were extracted for 27 target genes, earlier identified by our group as differentially expressed in EC vs ES (Alagaratnam et al. 2013).

For genomic identification of significant cancer related regions/genes, PCF segmented data for the primary ECs was used as input for the GISTIC 2.0.22 algorithm (Mermel et al. 2011). Copy number estimates $>0.1$ were called as copy number gain, while estimates $<-0.1$ were called as loss. The broad length cut-off was set to 0.5 (-brlen 0.5), the confidence level was set to 0.90 (-conf 0.90), normal arbitrated peel-off was performed (-armpeel 0), and we calculated the significance of deletions at a gene level (-genegistic 1), otherwise default settings. The reference genome file hg19.mat was used. Significant broad events were defined as events with a q-value $<0.05$, and significant focal events as events with q-values $<0.25$.

Preprocessed and normalized LRR and BAF data for the primary ECs was analysed using the allelespecific copy number analysis of tumours (ASCAT) v.2.3 algorithm to obtain allele-specific copy number estimates (Van Loo et al. 2010). ASCAT data were subsequently used to call regions with amplifications and $\mathrm{LOH}$.
However, as blood/germline DNA was not analysed, the LOH regions may include germline homozygous regions. By ASCAT, we also estimated ploidy and aberrant cell fraction of each tumour. The penalty parameter was set to 50 and discrete copy number states were determined relative to the median genome-wide copy number in each tumour sample.

The fraction of the genome with CNA or $\mathrm{LOH}$ was calculated as the number of aberrant bases out of the total number of bases with copy number and LOH estimate available, respectively.

Copy number estimates per gene were retrieved by mapping chromosomal segments from each sample to the $\mathrm{R}$ implemented transcript database TxDb.Hsapiens.UCSC. hg19.knownGene (v3.2.2) (Carlson et al. 2015), utilizing the findOverlaps function from the GenomicRanges $\mathrm{R}$ package (v1.28.3) (Lawrence et al. 2013). Gene symbols were collected using the R package org.Hs.eg.db (Carlson 2017) and updated to the approved symbols according to HUGO Gene Nomenclature Committee. For GISTIC, the output contains the genes located in the identified focal regions. However, to obtain a final target gene list, the regions identified with focal CNAs by GISTIC, were also manually examined for protein coding genes in Ensembl (Version 87, GRCh37) and these were added to the list of target genes. All genomic positions refer to genome version GRCh37 (hg19). Pseudogenes and genes annotated as non-coding in Ensembl were not considered.

Analysis of DNA and RNA level data from TCGA are described in the Supplementary Materials and methods (see section on supplementary materials given at the end of this article).

\section{Results}

DNA copy number aberrations in primary ECs, compared to EC and ES cell lines

By use of PCF segmentation, we identified similar CNAs in primary ECs and EC cell lines (Fig. 1). In general, the frequencies of CNAs were higher for EC cell lines than for primary EC tumours. The most frequent aberrations observed for primary ECs were gain of $12 p$ (100\% of the samples) and gains of the whole or parts of chromosomes 7, 8, and 17 and losses of the whole or parts of chromosomes $4,10,11,15$, and 18 (>30\%). From the PCF segmented data, apart from gain of $12 p$, the two most frequent aberrations were a region of gain at $7 \mathrm{p} 21$ $(12,327,848-14,412,764)$ and a region of loss at 10q11-q21 $(47,757,274-68,156,269)$. The $7 \mathrm{p} 21$ region, gained in

This work is licensed under a Creative Commons
Attribution 4.0 International License.



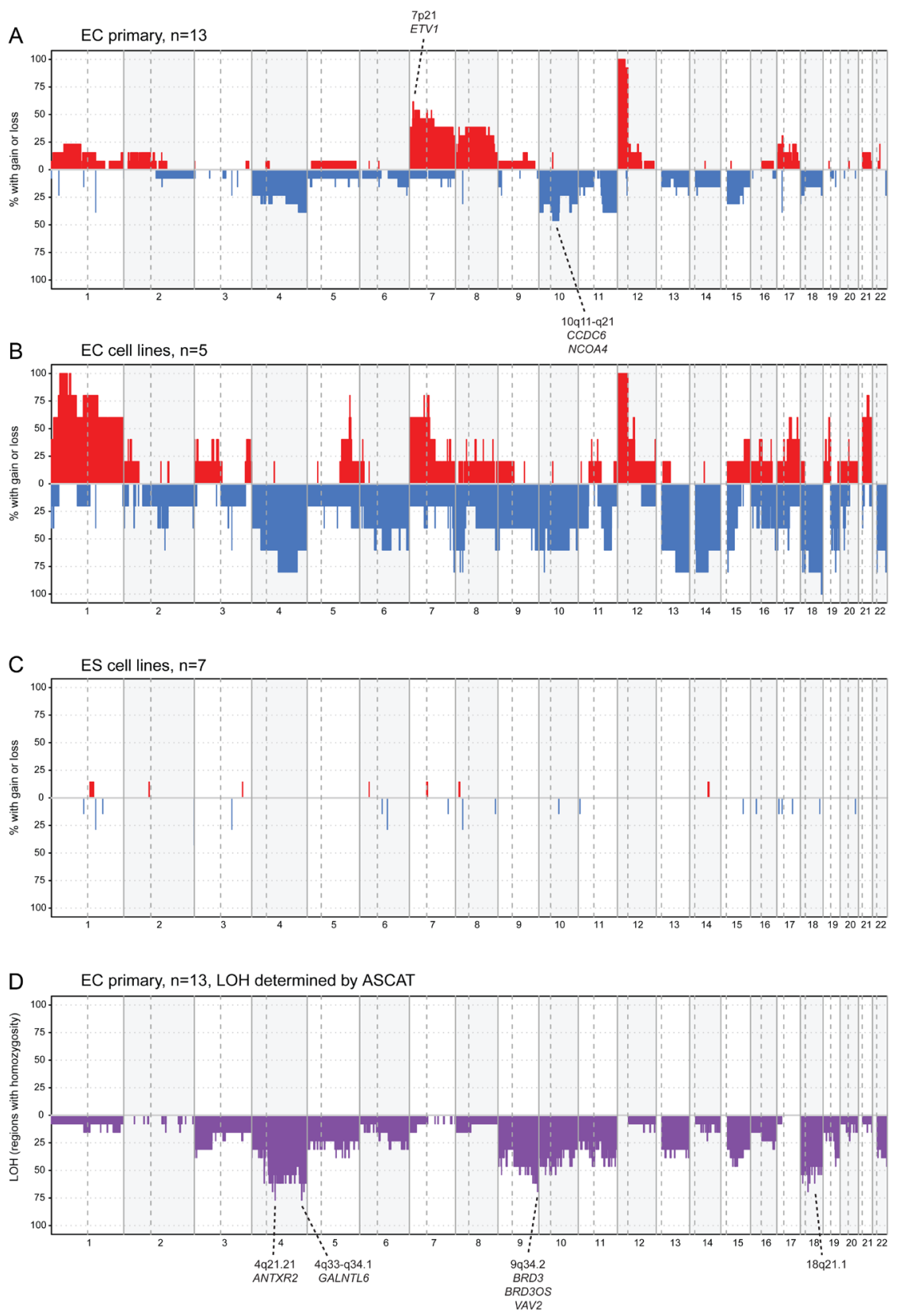

Figure 1

DNA copy number aberration frequency. Frequency plots showing gain (red) and loss (blue) identified from PCF segments, and data are plotted along chromosomes 1 to 22: (A) primary ECs $(n=13)$ with the two most frequent CNAs apart from the ubiquitous $12 \mathrm{p}$ amplification indicated; (B) EC cell lines ( $n=5)$; and (C) ES cell lines $(n=7)$. In (D) frequencies of $\mathrm{LOH}$ among the primary ECs and the genes located in the regions with highest frequency are shown.
8/13 (>60\%) ECs, contains only five genes (ARL4A, $D G K B, E T V 1, S C I N$, and $V W D E)$, whereas the region at 10q11-q21, lost in 6/13 (>45\%) ECs, contains 81 genes (Table 1). Among the affected genes, ETV1, CCDC6, and NCOA4 are causally implicated in cancer according to the Cancer Gene Census (Tate et al. 2019).

From the individual tumour CNA plots (Supplementary Fig. 1), we observed that the 13 primary ECs varied markedly in both number of gains and losses and the proportion of the genome affected by CNAs. The aberrations were typically broad events of chromosome arm-length, and median genome wide CNA for the
13 EC samples was $12 \%$ (mean 23\%; Supplementary Fig. 1). Three samples (EC 28, EC 1740, and EC 1838) had only nine percent genome wide CNA, whereas the two samples with the highest percent of aberrations (EC 1017 and EC 3113) had 53 and 56\% genome wide CNA.

We observed five recurrent, CNA regions in the seven early passage ES cell lines (Fig. 1 and Table 2), including focal loss in regions 1q21.3 and 3q22.1 (both in two ES cell lines). These regions overlap with larger segments of loss also found in primary ECs (Table 1) and covers the genes $L C E 1 E$ and $A L G 1 L 2$, respectively. 
Table 1 Focal aberration events identified in primary ECs.

\begin{tabular}{|c|c|c|c|c|c|}
\hline CNA type & Analysis & Cytoband & Start (bp) & End $(b p)$ & Segment size $(b p)$ \\
\hline Gain & PCF & $7 p 21$ & $12,327,848$ & $14,412,764$ & $2,084,916$ \\
\hline Gain & GISTIC & $12 \mathrm{p} 13.31$ & $7,974,004$ & $8,135,091$ & 161,087 \\
\hline Gain & GISTIC & $12 \mathrm{p} 11.1$ & $34,275,407$ & $37,857,943$ & $3,582,536$ \\
\hline Gain & GISTIC & $22 q 11.23$ & $25,682,781$ & $25,910,952$ & 228,171 \\
\hline Loss & GISTIC & 1 p36.11 & $25,571,270$ & $25,673,153$ & 101,883 \\
\hline Loss & GISTIC & $1 q 21.3$ & $152,747,127$ & $152,773,904$ & 26,777 \\
\hline Loss & GISTIC & $3 q 22.1$ & $129,695,715$ & $129,819,637$ & 123,922 \\
\hline Loss & PCF & $10 q 11-21$ & $47,757,274$ & $68,156,269$ & $20,398,995$ \\
\hline Loss & GISTIC & $11 q 11$ & $55,363,341$ & $55,541,283$ & 177,942 \\
\hline Loss & GISTIC & $17 p 11.2$ & $18,397,113$ & $18,441,307$ & 44,194 \\
\hline
\end{tabular}

\begin{tabular}{|c|}
\hline Genes in region \\
\hline $\begin{array}{l}\text { ARL4A, DGKB, ETV1, SCIN, VWDE } \\
\text { (ETV1 in COSMIC cancer gene census) }\end{array}$ \\
\hline$S L C 2 A 3, S L C 2 A 14$ \\
\hline- \\
\hline$\angle R P 5 L$ \\
\hline RSRP1a, RHD, TMEM50A a \\
\hline$\angle C E 1 D, L C E 1 E^{\mathrm{b}}, L C E 1 F$ \\
\hline$A L G 1 L 2^{\mathrm{b}}, T R H^{\mathrm{a}}$ \\
\hline $\begin{array}{l}81 \text { genes, including COSMIC cancer } \\
\text { genes: } \underline{C} \text { CDC } 6 \text { and NCOA4 }\end{array}$ \\
\hline OR4C6, OR4C11, OR4P4, OR4S2 \\
\hline LGALS9Ca \\
\hline
\end{tabular}

Regions of gain and loss significant by GISTIC analysis (FDR $q$ values $<0.25$ ) and the most frequent non-significant focal region of gain and loss identified by PCF segmentation are listed. Genes located in the corresponding region are presented to the right. aidentified from Ensembl; bldentified also in ES cell lines. CNA, copy number aberration.

\section{Significant DNA copy number events in primary ECs}

PCF-segmented data from the 13 primary ECs were analysed with GISTIC to identify statistically significant CNAs, both in terms of chromosome arm-level (broad; Supplementary Table 1) and focal events. We identified three significant focal regions of gain, located at 12p13.31, 12p11.1, and 22q11.23; and five significant focal regions of loss, located at 1p36.11, 1q21.3, 3q22.1, 11q11, and 17p11.2 (Table 1 and Supplementary Fig. 2). Although the $1 \mathrm{q} 21.3$ and $3 \mathrm{q} 22.1$ segments covers the LCE1E and ALG1L2 genes, also found to be lost in ES cell lines, they were not excluded from further analyses.

\section{Ploidy, allele-specific copy number profiles, and LOH in primary ECs}

Ploidy estimates for the 13 tumours, as calculated by the ASCAT algorithm, ranged from 2.3 to 5.0. The ploidy values formed two clusters, one between 2.3 and
2.8 (9/13 tumours) and one between 4.4 and 5.0 (4/13 tumours; Supplementary Fig. 3). Individual allelespecific profiles of the 13 tumours are shown in Supplementary Fig. 4.

The ASCAT analysis revealed a minimal amplicon of $100 \mathrm{kbp}$ (chr12: 8,024,362-8,123,900) that was present at 15 and 31 additional copies in two individual tumours and gained across all 13 tumours (Fig. 2). For 12/13 ECs, this amplicon was the segment, or was included within the $12 p$ segment, with the overall highest copy number. This segment contains the SLC2A3 gene and parts of SLC2A14.

LOH was determined from the allele-specific copy number profiles for the primary ECs (Fig. 1). The fraction of the genome with $\mathrm{LOH}$ varied from 15 to $42 \%$, with a median of $26 \%$. $\mathrm{LOH}$ was detected in one or more samples for all the autosomal chromosomes, and encompassed larger regions for 6 of 13 ECs on chromosome arms 4q, $9 \mathrm{q}, 18 \mathrm{p}$, and 18q. Within these broad regions of $\mathrm{LOH}$, four additional focal regions of $\mathrm{LOH}$ were detected

Table 2 Recurrent regions of loss in ES cell lines, showing loss in EC primary/cell lines.

\begin{tabular}{|c|c|c|}
\hline Cytoband & Cell line & start (bp) \\
\hline \multirow[t]{3}{*}{$2 q 37.3$} & $\mathrm{H} 7$ & $242,915,466$ \\
\hline & $\mathrm{H} 14$ & $242,915,466$ \\
\hline & Shef6 & $242,915,466$ \\
\hline \multirow[t]{2}{*}{$1 q 21.3$} & $\mathrm{H} 7$ & $152,759,678$ \\
\hline & Shef6 & $152,759,678$ \\
\hline \multirow[t]{2}{*}{$3 q 22.1$} & Shef6 & $129,766,586$ \\
\hline & Shef7 & $129,763,698$ \\
\hline \multirow[t]{2}{*}{$6 q 16.1$} & $\mathrm{H7}$ & $95,452,264$ \\
\hline & $\mathrm{H} 14$ & $95,442,761$ \\
\hline \multirow[t]{2}{*}{$8 p 21.2$} & $\mathrm{H} 7$ & $24,974,476$ \\
\hline & $\mathrm{H} 14$ & $24,974,522$ \\
\hline
\end{tabular}

https://erc.bioscientifica.com

https://doi.org/10.1530/ERC-20-0064

\begin{tabular}{c}
\hline End $(\mathrm{bp})$ \\
\hline $243,034,686$ \\
$243,089,456$ \\
$243,089,456$ \\
$152,768,700$ \\
$152,768,700$ \\
$129,806,236$ \\
$129,806,236$ \\
$95,533,338$ \\
$95,533,338$ \\
$24,984,333$ \\
$24,984,333$ \\
\hline
\end{tabular}

(c) 2020 The authors Published by Bioscientifica Ltd. Printed in Great Britain

\begin{tabular}{c}
\hline Segment size $(\mathrm{bp})$ \\
\hline 119,220 \\
173,990 \\
173,990 \\
9022 \\
9022 \\
39,650 \\
42,538 \\
81,074 \\
90,577 \\
9857 \\
9811
\end{tabular}

\begin{tabular}{|c|c|c|}
\hline $\begin{array}{c}\text { Mean } \log R \\
\text { ratio }\end{array}$ & $\begin{array}{c}\text { Detected in EC } \\
\text { cell lines }\end{array}$ & $\begin{array}{l}\text { Detected in } \\
\text { primary ECs }\end{array}$ \\
\hline-0.61 & & \\
\hline $\begin{array}{l}-0.49 \\
-0.49\end{array}$ & $2 / 5$ & $1 / 13$ \\
\hline $\begin{array}{l}-1.46 \\
-1.38\end{array}$ & $2 / 5$ & $5 / 13$ \\
\hline $\begin{array}{l}-0.96 \\
-0.70\end{array}$ & $3 / 5$ & $3 / 13$ \\
\hline $\begin{array}{l}-0.75 \\
-0.80\end{array}$ & $3 / 5$ & $0 / 13$ \\
\hline $\begin{array}{l}-1.12 \\
-1.34\end{array}$ & $4 / 5$ & $4 / 13$ \\
\hline
\end{tabular}

This work is licensed under a Creative Commons Attribution 4.0 International License. 


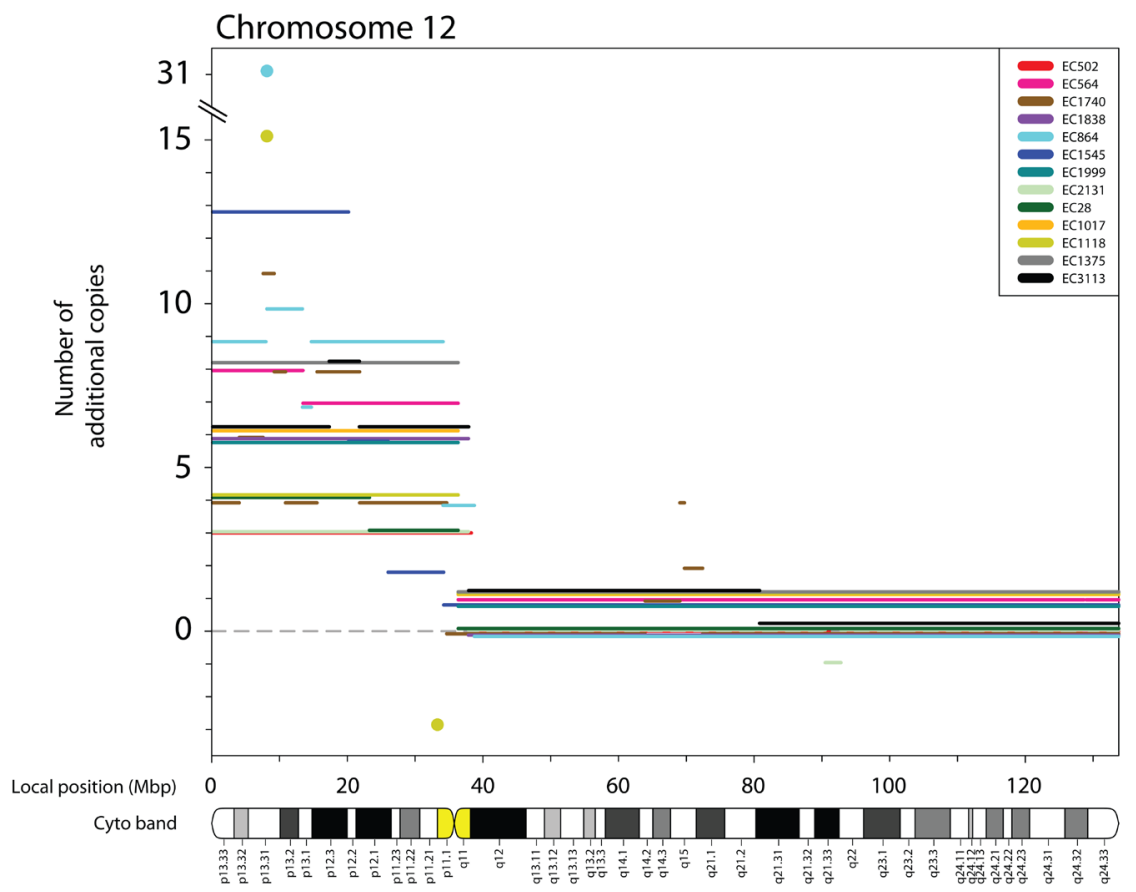

\section{Figure 2}

Minimal amplicon of $100 \mathrm{kbp}$ on chromosome arm 12p. Copy number aberrations on chromosome 12 from 13 primary ECs, plotted by median adjusted copy number, from ASCAT analysis and genomic position. To allow visibility of all DNA copy number chromosome 12 segments, for each tumour, the lines were adjusted. Segments $<0.5 \mathrm{Mb}$ are enlarged as circles to increase their visibility. (4q21.21, 4q33-q34.1, 9q34.2, and 18q12.1), indicated as peaks in Fig. 1, and present in at least 9 of the 13 ECs (Table 3). Interestingly, a region on chromosome arm 9q showed frequent LOH but no copy number loss (Fig. 1), and is thus a copy neutral LOH.

\section{Differentially expressed genes associated with DNA copy number levels}

In a previous study, we identified 28 differentially expressed genes between EC and ES cell lines (Alagaratnam et al. 2013). The relative gene expression and the corresponding copy number changes from PCF for 27 genes (one was located on chromosome $\mathrm{X}$ ) are shown for EC cell lines and tumours in Fig. 3. Six of the 16 genes with higher expression in EC compared to ES cell lines are localized on chromosome arm 12p (C12orf4, DPPA3, GOLT1B, NOP2, PARP11, and TULP3) and showed gain in all and amplification in most EC cell lines (4/5) and primary ECs (9/13). However, the 10 remaining genes, and the
11 genes with lower expression in EC compared to ES cell lines, were in regions with few CNAs.

\section{Identification of target genes affected by CNAs}

Within the identified regions of CNA or $\mathrm{LOH}$ in the EC subtype, there are several protein-coding genes of potential interest to EC development. There are 16 genes located in the GISTIC-defined focal loss or gain regions, five genes within the ASCAT-defined LOH regions and in the two regions showing the most frequent aberrations (apart from 12p), as identified by the PCF segmented data, there are three genes known to be cancer critical genes according to COSMIC. In addition, six genes previously identified as differentially expressed between EC and ES cell lines were also found to be gained or amplified in EC tumours. Taken together, we nominate 30 protein-coding genes affected by CNAs and/or LOH to be of interest to the EC subtype (Supplementary Table 2).

Table 3 Allele-specific LOH identified in primary ECs.

\begin{tabular}{|c|c|}
\hline Cytoband & Samples with LOH \\
\hline $4 q 21.21$ & 10 \\
\hline $4 q 33-q 34.1$ & 10 \\
\hline $9 q 34.2$ & 9 \\
\hline $18 q 12.1$ & 9 \\
\hline
\end{tabular}

$\begin{array}{r}\hline \text { Start }(\mathrm{bp}) \\ \hline 80,576,187 \\ 171,243,266 \\ 136,642,066 \\ 25,987,834 \\ \hline\end{array}$

$\begin{array}{r}\hline \text { End }(\mathrm{bp}) \\ \hline 81,079,422 \\ 172,739,515 \\ 136,992,038 \\ 26,905,128 \\ \hline\end{array}$

\begin{tabular}{c}
\hline Segment size $(b p)$ \\
\hline 503,235 \\
$1,496,249$ \\
349,972 \\
917,294
\end{tabular}

Genes in region ANTXR2

GALNTL6 BRD3, BRD3OS, VAV2

Focal regions of LOH identified by ASCAT in primary ECs with corresponding genes located in the region.

https://erc.bioscientifica.com https://doi.org/10.1530/ERC-20-0064 (c) 2020 The authors Published by Bioscientifica Ltd. Printed in Great Britain
This work is licensed under a Creative Commons Attribution 4.0 International License. 


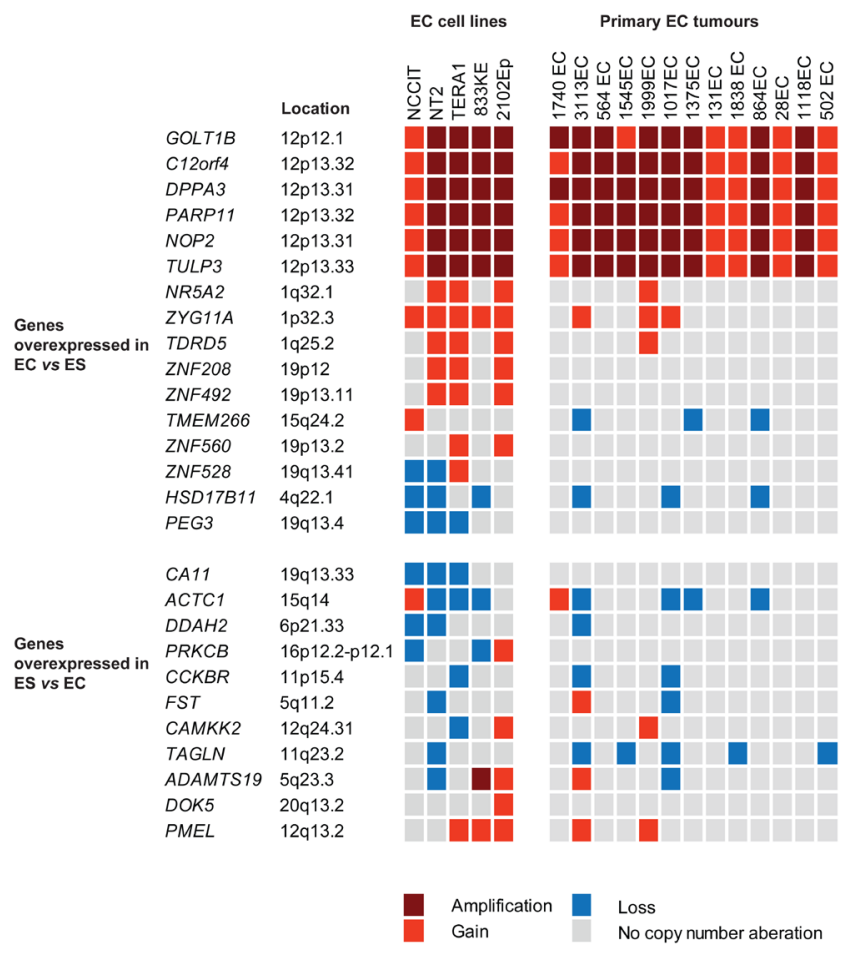

Figure 3

DNA copy number alteration and gene expression in EC. DNA copy number status for differentially expressed genes $(n=27)$ in EC cell lines versus ES cell lines, as identified in a previous study (Alagaratnam et al. 2013). The copy number status was determined by PCF for five EC cell lines and 13 primary ECs. Thresholds applied: loss <-0.15; gain>0.15; amplification $>0.45$

\section{DNA copy number and mRNA expression among TGCTs in TCGA data}

For further investigation of the genes affected by CNAs and/or LOH in ECs, we analysed copy number levels for 27 of the 150 TGCT tumours from TCGA classified as EC according to the ICD-O morphological codes (18 pure EC and 9 mixed). The genes identified at 12p, including $S L C 2 A 3$ and SLC2A14, were gained in all 27 samples and were highly amplified in 8 of the samples (30\%; Supplementary Fig. 5). ETV1, located at 7p21 was gained in 25 of the 27 samples, while CCDC6 and NCOA4 located at 10q11-q21 had copy number loss in 21 and 20 samples, respectively. Surprisingly, many of the genes located in focal regions identified as statistically significant loss in our cohort by GISTIC, for example, 1q21.3, 1p36.11 and 3q22.1, were infrequently lost in the EC cohort from TCGA (Supplementary Fig. 5).

A significant correlation $(\mathrm{q}<0.05)$ between DNA copy number and mRNA expression data was seen for 15 of the 30 genes. These were ETV1 and CCDC6 (from PCF-identified gain/loss); LRP5L and $S L C 2 A 3$ (from GISTIC-identified focal gain); TMEM5OA and TRH (from GISTIC-identified focal loss); ANTXR2, BRD3, $B R D 3 O S$, and VAV2 (from ASCAT-identified LOH); C12orf4, DPPA3, GOLT1B, NOP2 and PARP11 (previously identified as differentially expressed between EC and ES cell lines; Supplementary Fig. 5). Correlation between copy number and gene expression remained significant for four of the genes when only considering the EC subset $(n=27)$. This included a strong correlation for ETV1 $(\mathrm{R}=0.8, \mathrm{q}<0.0001)$.

\section{Somatic mutations among TGCTs in TCGA}

TCGA whole-exome sequencing data were examined for somatic mutations in the 30 genes. We found that six of the 150 TGCT samples contained markedly higher numbers of mutations genome-wide (median 1091.5 mutations), than the remaining TGCTs (median 38.5 mutations), and omitted these from further analysis. Among the included 144 tumour samples, 20 (4/20 diagnosed as EC) were found to harbour somatic, non-synonymous mutations in 11 of the 30 genes (Supplementary Table 3). Non-synonymous mutations in two or more TGCTs were identified in ANTXR2, LCE1F, SLC2A3, SLC2A14, and TULP3.

\section{Fusion transcript breakpoints including target genes/regions among TGCTs in TCGA}

Next, we evaluated whether CNAs were associated with generation of fusion genes. After analysis of RNA-sequencing data from TCGA's TGCT samples, the intersection of the outputs from two fusion finder software, FusionCatcher and deFuse, resulted in 1956 nominated fusion transcript breakpoints (range 2 to 49 per sample, median=10). None of these transcript breakpoints involved the 30 genes affected by CNAs. However, when considering breakpoints of fusion transcripts within $1 \mathrm{Mbp}$ of the identified CNA segments, we detected the previously described CLEC6A-CLEC4D read-through fusion transcripts (Hoff et al. 2016) in 12 of 150 TGCTs. Additionally, two fusion transcripts, LIN28A-CD52 and LRP6-LRRC23 were each detected in individual samples. Both these fusion transcripts were nominated with breakpoints joining the canonical exon-boundaries of the partner genes and are predicted to maintain reading frames (Table 4). These two fusion transcripts were however found to be predominantly expressed in the seminoma subtype of the TCGA samples (Table 4).

Interestingly, FusionCatcher and deFuse individually nominated a vast number of breakpoints involving

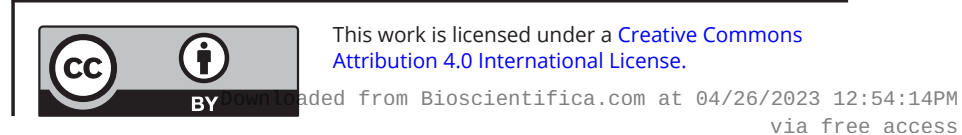


SLC2A3; 137 and 364, respectively. These breakpoints did not include the same partner genes in the individual samples and were therefore not considered in the intersected analysis. However, we observed that the number of breakpoints nominated per sample correlated between FusionCatcher and deFuse and that the nominated breakpoints were mostly in ECs and mixed germ cell tumours (16 and 15 out of in total 43, respectively; Supplementary Fig. 6). Overall in 150 TGCTs, the correlation between gene expression and DNA copy numbers of $S L C 2 A 3$ was significant (Spearman: $\left.\mathrm{R}=0.55, \mathrm{q}=9 \times 10^{-12}\right)$, whereas when only considering cases that had at least one nominated fusion breakpoint with SLC2A3 $(n=43)$, the correlation was not significant (Spearman: $R=0.26, P=0.09$ ).

\section{Discussion}

We have here performed high-resolution DNA copy number analysis of the EC subtype of TGCT, and identified broad and focal CNAs as well as allele-specific CNAs, including $\mathrm{LOH}$. We have nominated altogether 30 genes which may be related to EC within the regions affected by CNAs, including SLC2A3 from chromosome arm 12p and ETV1 on $7 \mathrm{p} 21$.

The CNA profiles varied in complexity among primary ECs. Both individual EC copy number profiles and the summarized overall CNA frequency plots, are in agreement with TGCT and EC profiles in particular (Kraggerud et al. 2002, Skotheim et al. 2006, Korkola et al. 2008), however, in this study with higher resolution than previously reported. Previous studies of the copy number landscape of EC include two aCGH studies $(n=25$ (Korkola et al. 2008) and $n=32$ (Gilbert et al. 2011)). Korkola et al. analysed several non-seminoma histological subtypes and did not find a prominent separation of subtypes on the basis of DNA copy number profiling, as opposed to the gene expression-based classification identified earlier (Korkola et al. 2005). However, Korkola et al. reported EC-specific genomic alterations at 1p33-31.2, 2p25.3, and 17p11.2-q21.32 (Korkola et al. 2008). Gilbert et al. profiled stage I ECs and identified novel minimal regions of overlap of gain at $6 \mathrm{p} 21.33,10 \mathrm{q} 11.21$, and $22 \mathrm{q} 13.32$, and of loss at 22q12.2. Our results are in agreement with alterations reported in these studies. However, apart from the common 12p gain and frequent $7 \mathrm{p}$ gain, none of the significant, focal CNA identified here were reported by Korkola et al. (2008) or Gilbert et al. (2011). To our knowledge, only one SNP microarray study 
has been published, including 18 pure ECs and 9 mixed TGCTs with a dominant EC proportion of in total 137 TGCTs (Shen et al. 2018). EC subtype-specific CNAs are not reported in this TCGA study; however, they report that ECs' CNA profiles cluster into three of five identified CNA groups. Among the focal, GISTIC-identified alterations in the TGCT cohort of TCGA, gain at 12p12 is in agreement with our results.

\section{ES and EC cell lines}

ES and EC cells have many common characteristics, and culture-adaptation of ES cells have been acknowledged as a model system for EC carcinogenesis (Andrews et al. 2005). All seven ES cell lines included are previously analysed for CNAs on SNP microarrays (Närvä et al. 2010, Amps et al. 2011). Aberrations, identified in individual cell lines at early passage were also found in our dataset, including gain at 2 p11.2 and 3q26.1. A recurrent gain on 20q11.21 in ES cell lines is suggested to confer a growth advantage (Amps et al. 2011). However, this gain is not found in the ES cell lines applied in our study. Also, none of the primary ECs showed gain of the 20q11.21 region. Still, among EC cell lines, two showed gain and one a borderline gain, supporting that this CNA may be induced by cell culturing rather than relevant for EC tumourigenesis.

\section{Ploidy estimates of ECs}

Ploidy estimates by ASCAT showed that 9/13 (69\%) of primary ECs were hyperdiploid to triploid, while 4/13 (31\%) were tetraploid to pentaploid. However, the algorithm gives an estimate of the on average ploidy and does not account for sub-clonality. This result is largely in agreement with previous studies, where ECs are often categorized as aneuploid or hypotriploid, and with flow cytometry often several aneuploid cell population are observed (Fosså et al. 1991, Burger et al. 1994). The near triploidy among ECs has also been shown in cytogenetic studies (Sandberg et al. 1996).

\section{High level amplification of the glucose transporters SLC2A3 and SLC2A14 in ECs}

Gain of $12 p$ was detected in all primary EC samples and EC cell lines, supporting its role as an early driver event in EC development. High-level amplification of $12 p$ segments has been reported in TGCT (Kraggerud et al. 2002, Skotheim et al. 2006), mostly focusing on a 12p11.2-p12.1 amplicon (Bourdon et al. 2002, Zafarana et al. 2003). Interestingly, we identified two novel segments with focal amplification; a $3.5 \mathrm{Mbp}$ segment on $12 \mathrm{p} 11.1$ with no annotated genes, and a $100 \mathrm{kbp}$ segment on $12 \mathrm{p} 13.31$. The latter segment corresponds to minimal amplicons present at estimated 15 and 31 additional copies in two individual ECs. This segment overlaps with both a larger region of amplification at 12p13 identified in a CGH study of TGCT cell lines (Henegariu et al. 2004) and a $200 \mathrm{kbp}$ region/ gene cluster at $12 \mathrm{p} 13.31$ that exhibits coordinated overexpression in both ECs and seminomas (Korkola et al. 2006). The small, $100 \mathrm{kbp}$ amplified region contains two glucose transporter genes, SLC2A3 and parts of SLC2A14.

Increased SLC2A3 expression is reported in TGCTs compared to normal testis (Rodriguez et al. 2003), and validated as a sensitive and specific marker for the EC and yolk sac tumour histological subtypes (Howitt et al. 2013). In vitro differentiation of EC cells, with subsequent loss of tumourigenic potential, is reported to repress several pluripotency genes at this locus, including $N A N O G$, GDF3, and DPPA3, but also SLC2A3 (Giuliano et al. 2005). SLC2A14 is a paralog of $S L C 2 A 3$ and with major expression in testis. We showed in data from TCGA, that the expression significantly correlates with copy number gains for SLC2A3, but not for SLC2A14. These results imply that amplification and over-expression of $S L C 2 A 3$ may be a common mechanism for activation. SLC2A3 and SLC2A14 were among the most frequently mutated of the investigated target genes (each observed with somatic mutation in three TCGA TGCTs, where one had an EC component). A large number of fusion transcript breakpoints were nominated for SLC2A3. Interestingly, expression of $S L C 2 A 3$ and DNA copy number did not correlate significantly for the samples that had nominated $S L C 2 A 3$ fusion breakpoints, which indicates that overexpression of $S L C 2 A 3$ in these cases is regulated by other mechanisms than the number of gene copies alone.

The roles of SLC2A14 and SLC2A3 in cancer have more recently gained attention. SLC2A14 (or GLUT14) expression is deregulated in several cancer types and is suggested to be a prognostic factor for a number of cancers, for example, in thyroid carcinoma (Chai et al. 2017). SLC2A3 (alias GLUT3) encodes a glucose transporter with a five-fold higher affinity for glucose than its ubiquitous family member GLUT1 (Simpson et al. 2008), making its expression an advantage in glucosepoor microenvironments with high glucose demands, such as in certain tumour environments. Indeed, SLC2A3 expression correlates with poor survival in several cancers, including brain and gastric cancers (Flavahan et al. 2013, 
Schlößer et al. 2017). While broad level gain of $12 p$ in TGCTs appears likely to confer the pluripotent phenotype for initiation of tumourigenesis, the focal amplification of the region containing $S L C 2 A 3$ may grant a proliferative advantage in progression and development of the tumour.

\section{CNAs at $7 p$ and $10 q$ affect the cancer critical genes ETV1 and CCDC6}

The second most frequently gained (after $12 p$ ) and the most frequently lost regions in ECs were located at $7 p$ and at 10q, respectively. Among the genes located in these regions, ETV1, CCDC6, and NCOA4 are known cancer critical genes. Several previous studies indicate that the functions of these genes are relevant in respect to TGCT development. Activated KIT is reported to prolong ETV1 protein stability and cooperate with ETV1 to promote tumorigenesis in gastrointestinal tumours (Chi et al. 2010). Disruption of the KIT-KITLG/MAPK signalling pathway is implicated in TGCT formation both as a predisposing germline risk factor and somatic driver event (Litchfield et al. 2015, 2017). ETV1 has been shown to upregulate the expression of androgen receptor target genes and promote autonomous testosterone production (Baena et al. 2013).

CCDC6 is a tumour-suppressor and a pro-apoptotic protein involved in DNA damage response and repair (Merolla et al. 2012). Loss of CCDC6 has been suggested to contribute to testicular neoplastic growth (Staibano et al. 2013) and could enhance tumour progression by impairing apoptosis following DNA damage (Cerrato et al. 2018). In effect, loss of CCDC6 has also been implicated as a biomarker to sensitizing cancer cells to treatment with PARP inhibitors (Cerrato et al. 2018).

\section{Fusion genes located on chromosome arm 12p}

We have previously identified novel fusion transcripts in TGCT (Hoff et al. 2016). In this study we analysed RNA sequencing data of TGCTs from the TCGA for the expression of fusion transcripts in proximity ( $1 \mathrm{Mbp}$ ) of identified regions of gain, loss, and LOH. We reasoned that CNAs may reflect structural rearrangements that form fusion genes. We repeatedly identified the fusion event CLEC6A-CLEC4D ( $n=12$ patients) and also two private fusion events, LIN28A-CD52 and LRP6-LRRC23. These fusions were, however, found expressed in non-EC histological subtypes (Table 4). Both genes involved in the CLEC6A-CLEC4D and the LRP6-LRRC23 fusion genes are located on chromosome arm 12p. Previously, we described several other private fusion genes on $12 \mathrm{p}$ (Hoff et al. 2016). The recurrent structural alterations of $12 p$ may be a common mechanism for the generation and expression of fusion genes in TGCT. However, the biological impact of these mostly private fusion gene events is uncertain.

In conclusion, by use of high-resolution SNP microarrays and advanced analyses, we present allelespecific copy number profiles for primary ECs and several novel focal CNAs. Within the regions affected by CNAs, we report 30 target genes that may be of interest to further our understanding of the EC subtype. High amplification of a $100 \mathrm{kbp}$ segment at $12 \mathrm{p} 13.31$ containing SLC2A3 was identified and the second most common CNA identified as gain at 7 p21 encompassed the cancer critical gene ETV1. Increasing DNA copy numbers were found to be correlated with increased gene expression of $S L C 2 A 3$ and ETV1.

\section{Supplementary materials}

This is linked to the online version of the paper at https://doi.org/10.1530/ ERC-20-0064.

\section{Declaration of interest}

The authors declare that there is no conflict of interest that could be perceived as prejudicing the impartiality of the research reported.

\section{Funding}

The study was supported by grants from the Norwegian Cancer Society (PR-2006-0442 to R A L and PR-2007-0166 to R I S), the Research Council of Norway, and the South-Eastern Norway Regional Health Authority. The authors also acknowledge NorStore, Notur, and Services for Sensitive Data at the University of Oslo for secure storage and processing of computer files and high-performance computation (projects NS9013S and NS9013K).

\section{Ethics approval and consent to participate}

The biobank is registered according to Norwegian legislation (no. 953; Biobank Registry of Norway) and the project has been approved by the Norwegian Committee for Medical and Health Research Ethics (S-05368 and S-07453b).

\section{Availability of data and materials}

The PCF segmented copy number data for the in-house analysed samples can be found in Supplementary Data and materials.

\section{Author contribution statement}

Study design: S A, S M K, A M H, O C L, P W A, R I S, R A L. Acquisition of data: S A, S M K, A M H, B J, K C G B, M H. Analyses and/or interpretation of data: all authors. Writing of the manuscript: $\mathrm{A} \mathrm{M} \mathrm{H}, \mathrm{S} \mathrm{M} \mathrm{K}$ and S A drafted the 
manuscript and all authors were involved in revision and have read and approved the final version. Study supervision: R I S and R A L.

\section{Acknowledgements}

The authors are grateful to Dr Vera M Abeler (Department of Pathology, The Norwegian Radium Hospital, Oslo University Hospital) for morphological evaluation of the patient samples. Furthermore, they thank Dr Kerstin Haase (The Francis Crick Institute, London NW1 1AT, UK) and Dr Peter van Loo (The Francis Crick Institute, London NW1 1AT, UK and Department of Human Genetics, University of Leuven, 3000 Leuven, Belgium) for discussions around and assistance with graphical representations of the ASCAT output.

\section{References}

Alagaratnam S, Harrison N, Bakken AC, Hoff AM, Jones M, Sveen A, Moore HD, Andrews PW, Lothe RA \& Skotheim RI 2013 Transforming pluripotency: an exon-level study of malignancyspecific transcripts in human embryonal carcinoma and embryonic stem cells. Stem Cells and Development 22 1136-1146. (https://doi. org/10.1089/scd.2012.0369)

Andrews PW, Matin MM, Bahrami AR, Damjanov I, Gokhale P \& Draper JS 2005 Embryonic stem (ES) cells and embryonal carcinoma (EC) cells: opposite sides of the same coin. Biochemical Society Transactions 33 1526-1530. (https://doi.org/10.1042/BST20051526)

Baena E, Shao Z, Linn DE, Glass K, Hamblen MJ, Fujiwara Y, Kim J, Nguyen M, Zhang X, Godinho FJ, et al. 2013 ETV1 directs androgen metabolism and confers aggressive prostate cancer in targeted mice and patients. Genes and Development 27 683-698. (https://doi. org/10.1101/gad.211011.112)

Baker DE, Harrison NJ, Maltby E, Smith K, Moore HD, Shaw PJ, Heath PR, Holden H \& Andrews PW 2007 Adaptation to culture of human embryonic stem cells and oncogenesis in vivo. Nature Biotechnology 25 207-215. (https://doi.org/10.1038/nbt1285)

Bourdon V, Naef F, Rao PH, Reuter V, Mok SC, Bosl GJ, Koul S, Murty VV, Kucherlapati RS \& Chaganti RS 2002 Genomic and expression analysis of the 12p11-p12 amplicon using EST arrays identifies two novel amplified and overexpressed genes. Cancer Research 62 6218-6223.

Brabrand S, Johannessen B, Axcrona U, Kraggerud SM, Berg KG, Bakken AC, Bruun J, Fosså SD, Lothe RA, Lehne G, et al. 2015 Exome sequencing of bilateral testicular germ cell tumors suggests independent development lineages. Neoplasia 17 167-174. (https:// doi.org/10.1016/j.neo.2014.12.005)

Burger RA, Witzsch U, Engel H, Potratz D \& Stockle M 1994 Automated image analysis DNA cytometry in testicular cancer. Urological Research 22 17-20. (https://doi.org/10.1007/BF00431543)

Carlson M 2017 org.Hs.eg.db: genome wide annotation for human. R Package Version 3.4.1. (https://doi.org/10.18129/B9.bioc.org.Hs.eg.db)

Carlson M \& Bioconductor Package Maintainer 2015 TxDb.Hsapiens. UCSC.hg19.knownGene: annotation package for TxDb Object(S), R Package Version 3.2.2. (https://doi.org/10.18129/B9.bioc.TxDb. Hsapiens.UCSC.hg19.knownGene)

Cerrato A, Merolla F, Morra F \& Celetti A 2018 CCDC6: the identity of a protein known to be partner in fusion. International Journal of Cancer 142 1300-1308. (https://doi.org/10.1002/ijc.31106)

Chai YJ, Yi JW, Oh SW, Kim YA, Yi KH, Kim JH \& Lee KE 2017 Upregulation of SLC2 (GLUT) family genes is related to poor survival outcomes in papillary thyroid carcinoma: analysis of data from the Cancer Genome Atlas. Surgery 161 188-194. (https://doi. org/10.1016/j.surg.2016.04.050)
Chi P, Chen Y, Zhang L, Guo XY, Wongvipat J, Shamu T, Fletcher JA, Dewell S, Maki RG, Zheng DY, et al. 2010 ETV1 is a lineage survival factor that cooperates with KIT in gastrointestinal stromal tumours. Nature 467 849-853-U117. (https://doi.org/10.1038/nature09409)

Chung CC, Kanetsky PA, Wang Z, Hildebrandt MA, Koster R, Skotheim RI, Kratz CP, Turnbull C, Cortessis VK, Bakken AC, et al. 2013 Meta-analysis identifies four new loci associated with testicular germ cell tumor. Nature Genetics 45 680-685. (https://doi. org/10.1038/ng.2634)

Flavahan WA, Wu Q, Hitomi M, Rahim N, Kim Y, Sloan AE, Weil RJ, Nakano I, Sarkaria JN, Stringer BW, et al. 2013 Brain tumor initiating cells adapt to restricted nutrition through preferential glucose uptake. Nature Neuroscience 16 1373-1382. (https://doi.org/10.1038/ nn.3510)

Fosså SD, Nesland JM, Wæhre H, Åmellem O \& Pettersen EO 1991 DNA ploidy in the primary tumor from patients with nonseminomatous testicular germ-cell tumors clinical stage-I. Cancer 67 1874-1877. (https://doi.org/10.1002/1097-0142(19910401)67:7<1874::aidcncr2820670710>3.0.co;2-6)

Gilbert DC, McIntyre A, Summersgill B, Missiaglia E, Goddard NC, Chandler I, Huddart RA \& Shipley J 2011 Minimum regions of genomic imbalance in stage I testicular embryonal carcinoma and association of 22q loss with relapse. Genes, Chromosomes and Cancer 50 186-195. (https://doi.org/10.1002/gcc.20843)

Giuliano CJ, Kerley-Hamilton JS, Bee T, Freemantle SJ, Manickaratnam R, Dmitrovsky E \& Spinella MJ 2005 Retinoic acid represses a cassette of candidate pluripotency chromosome $12 \mathrm{p}$ genes during induced loss of human embryonal carcinoma tumorigenicity. Biochimica et Biophysica Acta 1731 48-56. (https://doi.org/10.1016/j. bbaexp.2005.08.006)

Henegariu O, Heerema NA, Thurston V, Jung SH, Pera M \& Vance GH 2004 Characterization of gains, losses, and regional amplification in testicular germ cell tumor cell lines by comparative genomic hybridization. Cancer Genetics and Cytogenetics 148 14-20. (https:// doi.org/10.1016/s0165-4608(03)00211-5)

Hoff AM, Alagaratnam S, Zhao S, Bruun J, Andrews PW, Lothe RA \& Skotheim RI 2016 Identification of novel fusion genes in testicular germ cell tumors. Cancer Research 76 108-116. (https://doi. org/10.1158/0008-5472.CAN-15-1790)

Howitt BE, Brooks JD, Jones S \& Higgins JP 2013 Identification and characterization of 2 testicular germ cell markers, Glut3 and CyclinA2. Applied Immunohistochemistry and Molecular Morphology 21 401-407. (https://doi.org/10.1097/PAI.0b013e31827b505f)

International Stem Cell Initiative, Amps K, Andrews PW, Anyfantis G, Armstrong L, Avery S, Baharvand H, Baker J, Baker D, Munoz MB, et al. 2011 Screening ethnically diverse human embryonic stem cells identifies a chromosome 20 minimal amplicon conferring growth advantage. Nature Biotechnology 29 1132-1144. (https://doi. org/10.1038/nbt.2051)

Korkola JE, Heck S, Olshen AB, Reuter VE, Bosl GJ, Houldsworth J \& Chaganti RSK 2008 In vivo differentiation and genomic evolution in adult male germ cell tumors. Genes, Chromosomes and Cancer $\mathbf{4 7}$ 43-55. (https://doi.org/10.1002/gcc.20504)

Korkola JE, Houldsworth J, Dobrzynski D, Olshen AB, Reuter VE, Bosl GJ \& Chaganti RSK 2005 Gene expression-based classification of nonseminomatous male germ cell tumors. Oncogene 24 5101-5107. (https://doi.org/10.1038/sj.onc.1208694)

Korkola JE, Houldsworth J, Chadalavada RS, Olshen AB, Dobrzynski D, Reuter VE, Bosl GJ \& Chaganti RS 2006 Down-regulation of stem cell genes, including those in a $200-\mathrm{kb}$ gene cluster at $12 \mathrm{p} 13.31$, is associated with in vivo differentiation of human male germ cell tumors. Cancer Research 66 820-827. (https://doi.org/10.1158/00085472.CAN-05-2445)

Kraggerud SM, Skotheim RI, Szymanska J, Eknaes M, Fosså SD, Stenwig AE, Peltomäki P \& Lothe RA 2002 Genome profiles of familial/bilateral and sporadic testicular germ cell tumors.

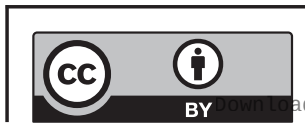

This work is licensed under a Creative Commons Attribution 4.0 International License. ded from Bioscientifica.com at 04/26/2023 12:54:14PM 
Genes, Chromosomes and Cancer 34 168-174. (https://doi. org/10.1002/gcc.10058)

Kraggerud SM, Oldenburg J, Alnæs GI, Berg M, Kristensen VN, Fosså SD \& Lothe RA 2009 Functional glutathione S-transferase genotypes among testicular germ cell tumor survivors: associations with primary and post-chemotherapy tumor histology. Pharmacogenetics and Genomics 19 751-759. (https://doi.org/10.1097/FPC.0b013e3283304253)

Lawrence M, Huber W, Pages H, Aboyoun P, Carlson M, Gentleman R, Morgan MT \& Carey VJ 2013 Software for computing and annotating genomic ranges. PLoS Computational Biology 9 e1003118. (https://doi.org/10.1371/journal.pcbi.1003118)

Litchfield K, Summersgill B, Yost S, Sultana R, Labreche K, Dudakia D, Renwick A, Seal S, Al-Saadi R, Broderick P, et al. 2015 Whole-exome sequencing reveals the mutational spectrum of testicular germ cell tumours. Nature Communications 6 5973. (https://doi.org/10.1038/ ncomms6973)

Litchfield K, Levy M, Orlando G, Loveday C, Law PJ, Migliorini G, Holroyd A, Broderick P, Karlsson R, Haugen TB, et al. 2017 Identification of 19 new risk loci and potential regulatory mechanisms influencing susceptibility to testicular germ cell tumor. Nature Genetics 49 1133-1140. (https://doi.org/10.1038/ng.3896)

Lothe RA, Peltomaki P, Tommerup N, Fossa SD, Stenwig AE, Borresen AL \& Nesland JM 1995 Molecular-genetic changes in human male germcell tumors. Laboratory Investigation 73 606-614.

Mermel CH, Schumacher SE, Hill B, Meyerson ML, Beroukhim R \& Getz G 2011 GISTIC2.0 facilitates sensitive and confident localization of the targets of focal somatic copy-number alteration in human cancers. Genome Biology 12 R41-R41. (https://doi. org/10.1186/gb-2011-12-4-r41)

Merolla F, Luise C, Muller MT, Pacelli R, Fusco A \& Celetti A 2012 Loss of CCDC6, the first identified RET partner gene, affects pH2AX S139 levels and accelerates mitotic entry upon DNA damage. PLOS ONE 7 e36177. (https://doi.org/10.1371/journal.pone.0036177)

Närvä E, Autio R, Rahkonen N, Kong L, Harrison N, Kitsberg D, Borghese L, Itskovitz-Eldor J, Rasool O, Dvorak P, et al. 2010 Highresolution DNA analysis of human embryonic stem cell lines reveals culture-induced copy number changes and loss of heterozygosity. Nature Biotechnology 28 371-377. (https://doi. org/10.1038/nbt.1615)

Noone AM, Howlader N, Krapcho MM, Brest A, Yu MR, Tatalovich JZ, Mariotto A, Lewis DR, Chen HS, Feuer EJ, et al. 2018 SEER Cancer Statistics Review, Testicular Cancer, 1975-2015. Bethesda, MD, USA: National Cancer Institute.

Oldenburg J, Kraggerud SM, Brydøy M, Cvancarova M, Lothe RA \& Fosså SD 2007 Association between long-term neuro-toxicities in testicular cancer survivors and polymorphisms in glutathione-stransferase-P1 and -M1, a retrospective cross sectional study. Journal of Translational Medicine 5 70. (https://doi.org/10.1186/1479-5876-5-70)

Oosterhuis JW, Castedo SMMJ, Dejong B, Cornelisse CJ, Dam A, Sleijfer DT \& Koops HS 1989 Ploidy of primary germ-cell tumors of the testis - pathogenetic and clinical relevance. Laboratory Investigation 60 14-21.

Rajpert-De Meyts E, McGlynn KA, Okamoto K, Jewett MA \& Bokemeyer C 2016 Testicular germ cell tumours. Lancet $\mathbf{3 8 7}$ 1762-1774. (https://doi.org/10.1016/S0140-6736(15)00991-5)

Rodriguez S, Jafer O, Goker H, Summersgill BM, Zafarana G, Gillis AJ, van Gurp RJ, Oosterhuis JW, Lu YJ, Huddart R, et al. 2003 Expression profile of genes from 12p in testicular germ cell tumors of adolescents and adults associated with i(12p) and amplification at 12p11.2-p12.1. Oncogene 22 1880-1891. (https://doi.org/10.1038/sj.onc.1206302)
Rosen A, Jayram G, Drazer M \& Eggener SE 2011 Global trends in testicular cancer incidence and mortality. European Urology 60 374-379. (https://doi.org/10.1016/j.eururo.2011.05.004)

Sandberg AA, Meloni AM \& Suijkerbuijk RF 1996 Reviews of chromosome studies in urological tumors. III. Cytogenetics and genes in testicular tumors. Journal of Urology 155 1531-1556. (https://doi.org/10.1016/S0022-5347(01)66124-X)

Schlößer HA, Drebber U, Urbanski A, Haase S, Baltin C, Berlth F, Neiß S, von Bergwelt-Baildon M, Fetzner UK, Warnecke-Eberz U, et al. 2017 Glucose transporters 1, 3, 6, and 10 are expressed in gastric cancer and glucose transporter 3 is associated with UICC stage and survival. Gastric Cancer 20 83-91. (https://doi.org/10.1007/s10120-015-0577-x)

Shen H, Shih J, Hollern DP, Wang LH, Bowlby R, Tickoo SK, Thorsson V, Mungall AJ, Newton Y, Hegde AM, et al. 2018 Integrated molecular characterization of testicular germ cell tumors. Cell Reports $\mathbf{2 3}$ 3392-3406. (https://doi.org/10.1016/j.celrep.2018.05.039)

Simpson IA, Dwyer D, Malide D, Moley KH, Travis A \& Vannucci SJ 2008 The facilitative glucose transporter GLUT3: 20 years of distinction. American Journal of Physiology: Endocrinology and Metabolism 295 E242-E253. (https://doi.org/10.1152/ ajpendo.90388.2008)

Skotheim RI, Autio R, Lind GE, Kraggerud SM, Andrews PW, Monni O, Kallioniemi O \& Lothe RA 2006 Novel genomic aberrations in testicular germ cell tumors by array-CGH, and associated gene expression changes. Cellular Oncology 28 315-326. (https://doi. org/10.1155/2006/219786)

Staibano S, Ilardi G, Leone V, Luise C, Merolla F, Esposito F, Morra F, Siano M, Franco R, Fusco A, et al. 2013 Critical role of CCDC6 in the neoplastic growth of testicular germ cell tumors. BMC Cancer $\mathbf{1 3}$ 433. (https://doi.org/10.1186/1471-2407-13-433)

Sveen A, Løes IM, Alagaratnam S, Nilsen G, Høland M, Lingjærde OC, Sorbye H, Berg KCG, Horn A, Angelsen JH, et al. 2016 Intra-patient inter-metastatic genetic heterogeneity in colorectal cancer as a key determinant of survival after curative liver resection. PLoS Genetics 12 e1006225. (https://doi.org/10.1371/journal.pgen.1006225)

Tate JG, Bamford S, Jubb HC, Sondka Z, Beare DM, Bindal N, Boutselakis H, Cole CG, Creatore C, Dawson E, et al. 2019 COSMIC: the catalogue of somatic mutations in cancer. Nucleic Acids Research 47 D941-D947. (https://doi.org/10.1093/nar/gky1015)

Taylor-Weiner A, Zack T, O'Donnell E, Guerriero JL, Bernard B, Reddy A, Han GC, AlDubayan S, Amin-Mansour A, Schumacher SE, et al. 2016 Genomic evolution and chemoresistance in germ-cell tumours. Nature 540 114-118. (https://doi.org/10.1038/nature20596)

Van Loo P, Nordgard SH, Lingjaerde OC, Russnes HG, Rye IH, Sun W, Weigman VJ, Marynen P, Zetterberg A, Naume B, et al. 2010 Allelespecific copy number analysis of tumors. PNAS 107 16910-16915. (https://doi.org/10.1073/pnas.1009843107)

Voutsadakis IA 2014 The chemosensitivity of testicular germ cell tumors. Cellular Oncology 37 79-94. (https://doi.org/10.1007/s13402-0140168-6)

Wang ZM, McGlynn KA, Rajpert-De Meyts E, Bishop DT, Chung CC, Dalgaard MD, Greene MH, Gupta R, Grotmol T, Haugen TB, et al. 2017 Meta-analysis of five genome-wide association studies identifies multiple new loci associated with testicular germ cell tumor. Nature Genetics 49 1141-1147. (https://doi.org/10.1038/ng.3879)

Zafarana G, Grygalewicz B, Gillis AJ, Vissers LE, van de Vliet W, van Gurp RJ, Stoop H, Debiec-Rychter M, Oosterhuis JW, van Kessel AG, et al. 2003 12p-amplicon structure analysis in testicular germ cell tumors of adolescents and adults by array CGH. Oncogene 22 7695-7701. (https://doi.org/10.1038/sj.onc.1207011) https://erc.bioscientifica.com https://doi.org/10.1530/ERC-20-0064 (c) 2020 The authors Published by Bioscientifica Ltd. Printed in Great Britain
Received in final form 11 May 2020

Accepted 10 June 2020

Accepted Manuscript published online 11 June 2020
This work is licensed under a Creative Commons Attribution 4.0 International License. 